\title{
Mindfulness Meditation in Diabetes
}

\author{
An Expert Interview with Sanjay Kalra
}

Department of Endocrinology, Bharti Hospital, Karnal, India

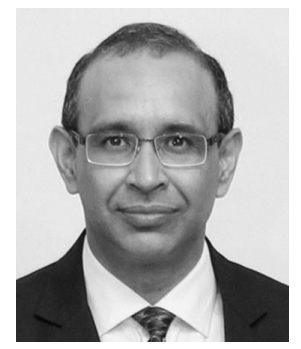

\section{Sanjay Kalra}

An endocrinologist by profession, Dr Sanjay Kalra works at Bharti Hospital, Karnal, Haryana. Executive Editor of the Indian Journal Endocrinology (IJEM) from 2011-2015; he is also Associate Editor, Diabetic Medicine (UK); Section Editor, Diabetes, of the Endocrine Society of India (ESI) Manual of Clinical Endocrinology (1st and 2nd editions), and Section Editor, Endocrinology, of the Association of Physician of India (API) Textbook of Medicine, 11th edition. As Vice-President of South Asian Federation of Endocrine Societies (SAFES), he remains busy in clinical care, patient education, research, and medical writing. He won the global DAWN Award for best translational research in diabetes in 2009. In his spare time, Dr Kalra likes to indulge in his favorite hobby, the Punjabi folk dance bhangra.

DOl: https://doi.org/10.17925/USE.2018.14.1.18

\section{Keywords}

Mindfulness, meditation, diabetes, patient care

Disclosure: Sanjay Kalra has nothing to disclose in relation to this paper.

Review Process: This article is a short interview piece with a member of the Editorial Board and has not been submitted to external peer reviewers.

Authorship: All named authors meet the International Committee of Medical Journal Editors (ICMJE) criteria for authorship of this manuscript, take responsibility for the integrity of the work as a whole, and have given final approval to the version to be published.

open Access: This article is published under the Creative Commons Attribution Noncommercial License, which permits any noncommercial use, distribution, adaptation, and reproduction provided the original author(s) and source are given appropriate credit. (c) The Authors 2018

Received: April 15, 2018

Published Online: May 22, 2018

Citation: US Endocrinology, 2018;14(1):18-19

Corresponding Author: Sanjay Kalra,

Department of Endocrinology, Bharti Hospital,

Karnal, India. E: bridekn|@gmail.com

Support: No funding was received in

the publication of this article.
$\mathrm{T}$ he prevalence of type 2 diabetes is increasing worldwide, and the cost of managing this global epidemic is considerable, particularly in developing countries with poorer health care systems. ${ }^{1}$ There is, therefore, a need for a more holistic approach to diabetes management, which focuses on all aspects of diabetes, from managing blood glucose to addressing the emotional and social aspects of living with diabetes. In an expert interview, Sanjay Kalra of the Bharti Hospital, Karnal, India, discusses the role of mindfulness meditation (MM), which is the practice of working with concentrated awareness to live each moment fully, in the management of diabetes.

\section{Q. Why is there a need for a psychosocial approach to the management of diabetes?}

Diabetes is a multifaceted disorder, which can impact every organ-system of the body. Apart from its biomedical complications, diabetes also influences the emotional, mental, and social domains of health. The lifestyle modification that is required to manage diabetes also creates discomfort, which in turn may be perceived as a burden. Poor psychosocial health may also impair biomedical health, and lead to suboptimal glycemic control. Thus, psychosocial wellbeing is a not only a desired target, but also a tool to achieving this target. To address all these issues, it is essential to view diabetes from a biopsychosocial prism. This helps us understand diabetes from a $360^{\circ}$ perspective, and put in place management strategies which ensure comprehensive biomedical and psychosocial health.

\section{Q. What are the benefits of mindfulness meditation as opposed to other holistic practices such as yoga?}

MM is a mind-body medicine which is distinct from yoga. However, these is significant overlap between the two therapies. While yoga includes flexibility and balance exercises, MM is mind-based exercise. At the same time, it must be noted that yoga includes MM as one of the eight steps to achieve realization. MM may help to modulate neurocognitive, endocrine, cardiovascular, and immune function without physical activity. ${ }^{2}$ Thus, there are no locomotor or musculoskeletal contraindications or limitations to its usage. 


\section{Q. What specific effects of meditation may be beneficial for people with diabetes?}

Though diabetes is a heterogenous disorder, with multiple clinical manifestations, its chronic complications occur due to vascular (endothelial) dysfunction. MM helps by improving the autonomic and endocrine regulation of vascular tone, thus leading to better cardiovascular health. ${ }^{3}$

The natural course of diabetes is also influenced by the brain. The neurocognitive relaxation experienced with $\mathrm{MM}$ can help reduce counter regulatory hormone levels. Muscle contraction and relaxation, which may be a part of $\mathrm{MM}$, may assist in improving sensitivity at skeletal muscle insulin receptors.

\section{Q. What evidence supports the benefit of meditation in people with diabetes?}

MM in diabetes care is backed by evidence. Randomized controlled trials have demonstrated the efficacy of $\mathrm{MM}$ in improving glycemic control, ${ }^{4-6}$ managing painful diabetic neuropathy, ${ }^{7}$ correcting eating disorders, and alleviating depression. ${ }^{8}$ The benefits of MM on emotional distress and quality of life are also proven. MM has been found to be well accepted by participants in multiple studies. ${ }^{9}$ It can be used as a self-help strategy, and therefore could reduce the burden on health care systems.

\section{Q. What are the potential negative effects of mindfulness meditation in people with diabetes?}

One must be cognizant of possible adverse effects of MM. Authors have described negative effects such as "relaxation induced anxiety and panic", paradoxical tension, and parasympathetic rebound. These effects occur with both short- and long-term meditation. Therefore, MM must be prescribed only after diligent screening, and should be monitored carefully. Persons with acute or unstable psychiatric conditions may not be good condition for MM. $\square$
1. NCD Risk Factor Collaboration (NCD-RisC). Worldwide trends in diabetes since 1980: a pooled analysis of 751 population-based studies with 4.4 million participants. Lancet. 2016:387:1513-30. 2. Baum A. Stress, intrusive imagery, and chronic distress. Health Psychol. 1990;9:653-75.

3. Levine GN, Lange RA, Bairey-Merz CN, et al. Meditation and cardiovascular risk reduction: a scientific statement from the American Heart Association. J Am Heart Assoc. 2017;6. pii:e002218. doi:10.1161/JAHA.117.002218.

4. Rosenzweig S, Reibel DK, Greeson JM, et al. Mindfulness-based stress reduction is associated with improved glycemic control in type 2 diabetes mellitus: a pilot study. Altern Ther Health Med. $2007 \cdot 13 \cdot 36-8$

5. Gainey A, Himathongkam T, Tanaka H, Suksom D. Effects of Buddhist walking meditation on glycemic control and vascular function in patients with type 2 diabetes. Complemet Ther Med 2016;26:92-7

6. Chaiopanont S. Hypoglycemic effect of sitting breathing meditation exercise on type 2 diabetes at Wat Khae Nok Primary Health Center in Nonthaburi province. J Med Assoc Thai. 2008:91:93-8.
7. Teixeira $E$. The effect of mindfulness meditation on painful diabetic neuropathy in adults older than 50 years. Holist Nurs Pract. 2010:24:277-83.

8. Rungreangkulkij S, Wongtakee W, Thongyot S. Buddhist group therapy for diabetes patients with depressive symptoms. Arch Psychiatr Nurs. 2011;25:195-205.

9. Kelley GA, Kelley KS. Meditative movement therapies an health-related quality-of-life in adults: a systematic review of meta-analyses. PLoS One. 2015;10:e0129181. doi: 10.1371/ journal. pone. 0129181 . 